\title{
The grammatical characterization of developmental dysphasia*
}

HARALD CLAHSEN

\section{Abstract}

This paper deals with child-language-acquisition disorders in the area of grammar, and it presents some of the results from our research study on developmental dysphasia in German children. An attempt is made to characterize dysphasia in terms of a selective deficit of an otherwise normal linguistic system. It is argued that dysphasic children have problems in establishing agreement relations in grammar. As is shown for various grammatical phenomena, such as word order, inflectional morphology, word classes, and types of constituents, this condition accounts for the structures which are blocked in dysphasia as well as for those which are still accessible to the children.

\section{Introduction}

The field of child-language disorders has traditionally been a domain of medicine, psychology, and educational disciplines. Linguistics and linguistically oriented language-acquisition research, however, have neglected this whole field. My major aim is to show that linguistic studies of child-language disorders can contribute solutions to both practical and theoretical problems in that field. Moreover, I suggest that results from language-development disorders are relevant to theories of acquisition as well. As far as clinical practice is concerned, linguistic studies allow us to improve particularly the diagnosis of child-language disorders. In our research group we have developed a procedure which can be used to describe the grammatical systems of language-disordered children and to assess their level of linguistic development (Clahsen 1986b). This procedure is now being used as a method of linguistic diagnosis at several speech-therapy institutions and clinics which are collaborating with our research group. In the next section, a brief description of the procedure 
will be given. My major concern in the present paper is to show that linguistic studies can also contribute to our theoretical understanding of child-language disorders. This will be done for developmental dysphasia using empirical results from our research study. ${ }^{1}$

According to the dominant research paradigm used in studies on childlanguage disorders, some salient linguistic properties from the children's language are selected and then correlated with various nonlinguistic features, such as general intelligence, auditory perception, hierarchical structuring abilities, etc. The aim is to find the causes of the children's linguistic problems. Thus, under such an approach, an explanation is given by deriving linguistic behavior from nonlinguistic deficits.

A linguistic approach introduces a different way of looking at childlanguage disorders. Linguistics regards language as a cognitive domain which is to a certain extent autonomous from nonlinguistic systems. From this it follows that there can be selective deficits within the linguistic domain, which need not necessarily correlate with other nonlinguistic disorders. Under a linguistic approach, it could be that at least certain kinds of child-language-acquisition disorders are explicable in terms of selective deficits of the language faculty itself. Grammar, that is, syntax and morphology, is generally assumed to be autonomous from other cognitive domains. Therefore, a linguistic approach has probably the most to say about the grammatical aspects of language-acquisition disorders. This is the main reason why in our research project we study the linguistic behaviour of a particular subgroup of language-disordered children, namely those with developmental dysphasia.

\section{Dysphasia}

The notion of dysphasia is used in the clinical literature (see Wyke 1978; Dannenbauer 1983), as a cover term for children with retarded development of language and/or severe problems with the normal acquisition of grammar. These children do not have any clear primary deficit, that is, they have normal nonverbal IQs, no hearing deficits, and no obvious emotional or behavioral disturbances. Given these rather rough criteria, it is to be expected that the syndrome does not cover a homogeneous population and that there is a lot of variation and several different types of dysphasia. In general, however, problems with the normal acquisition of grammar should be at the core of dysphasia. There are not many research studies available on developmental dysphasia. What is clearly missing is a detailed linguistic analysis of the grammatical systems developed by these children. Our research study should fill this gap. 
The general picture that emerges from the data of our research study is that in dysphasic children not all the components of grammar are equally disturbed. As will be shown below, the children mainly have problems in the area of inflectional morphology. The syntax, however, provides for the required positions. Word order within constituents is usually correct, and the children do not use idiosyncratic or defective syntactic rules. Moreover, it can be shown that the observed word-order errors, for example the dominant use of verb-final patterns in German dysphasics, are only secondary effects of the children's problems with morphology.

Based on these results, I will suggest a new characterization of dysphasia. It is an attempt to account for the specific grammatical problems of dysphasic children in terms of a selective deficit of an otherwise normal grammatical system. In particular, I will argue that the grammatical deficits that occur in dysphasic children have to do with problems in establishing agreement relations in grammar.

In what follows, I will first give a brief outline of the research questions and the hypotheses which are addressed in our project, as well as a short description of the data which we have analyzed so far. Then, I will present some of our empirical results and suggest grammatical analyses of the data.

\section{The Düsseldorf study on dysphasia}

\subsection{Research questions and hypotheses}

Our project on dysphasia should contribute answers to the following research questions:

(1) a. What do the grammatical systems of dysphasic children look like?

b. What are the principles that guide the development of their grammatical systems?

c. What are the learning mechanisms that the children use to acquire their grammatical systems?

d. Can we establish a linguistically based typology of different types of dysphasia?

The null hypothesis in our research study is that dysphasic children possess the same learning mechanisms and language-acquisition devices as normal children. This may be called the similarity assumption; it should 
not be rejected until the data leave no other choice. Therefore, in the absence of empirical evidence to the contrary, we try to describe the linguistic systems developed by dysphasic children under the assumption of similarity. This is meant as a strategy to prevent us from assuming global deficits in cases in which selective deficits would suffice to account for the data.

We assume as our general working hypothesis that developmental dysphasia can be defined in terms of selective deficits of the language acquisition device (see [1c]). In order to maintain that claim it has to be shown that the grammatical problems of dysphasic children are due to disorders of particular language-learning mechanisms or components of the language-acquisition device. The theoretical framework we adopt for our claims is the generative view of the language faculty (see Chomsky 1986) and related acquisition research, particularly the theory of learnability (see Pinker 1984; Hyams 1986). These theories specify what the components of the language faculty are and what language-learning mechanisms may look like. According to these theories, the knowledge of language and the mechanisms to acquire it are, at least in certain essential parts, modular and autonomous from other cognitive domains.

Furthermore, we expect to find different types of dysphasia (see [1d]). It could be, for example, that the mechanisms for building up phrasestructure trees are disturbed, while the morphology and the rest of the lexicon have developed just as with normal children. It could also be the other way around. In this case we would find that the dysphasic child can build up correct phrase-structure trees but has problems, for instance, with constructing morphological paradigms in the lexicon. Thus, the theory we adopt allows for several well-defined options which can be used to establish a linguistically based typology of dysphasia.

With reference to research question (1a), we assume that dysphasic children construct possible grammars. Given the selective-deficit hypothesis, we would not expect the children to construct bizarre rule systems, but rather grammars that are possible for human language. This does not mean that the children's grammars must be identical to the adults' grammar, but rather that the linguistic representations of dysphasic children fall under the limits imposed by universal principles. With respect to research question (1b), we would expect an unbalanced development of grammatical competence in dysphasic children. This is, at least, what can be predicted from the hypothesis of selective deficits, since, provided that there is a selective deficit in a particular component of the acquisition device, there should be no developmental progress in that area, or at least less progress than in other linguistic areas for which no deficit has been assumed. 


\subsection{Data}

In order to study these hypotheses, two sets of data have been gathered: (i) spontaneous speech samples from ten dysphasic children, mainly crosssectional and some longitudinal data (see Table 1 below) and (ii) spontaneous-speech samples and elicitation data from 20 dysphasic children studied longitudinally over a period of one year. All the children we study are German-speaking monolinguals, and they are treated by speech therapists in clinics or other speech-therapy institutions. Independently from our studies, the children have been assessed as dysphasics by speech therapists on the basis of the criteria mentioned above. The spontaneousspeech samples consist of recordings of unstructured play sessions. Each recording lasts for about one hour. Participants are the child and the speech therapist or another adult whom the child is familiar with. The recordings take place in the institutions and clinics where the children are treated. After the recording sessions, transcripts are made, consisting of at least 100 consecutive utterances by the child for each recording. These transcripts, which are double-checked, provide the data base for the grammatical analysis.

The data of sets (i) and (ii) are analyzed with regard to the main properties of syntax and inflectional morphology, such as word order, constituent structure, negation, question formation, case markings, verb morphology, plural morphology. For this purpose, a computerized version of the profile analysis is used as a descriptive tool. ${ }^{2}$

The profile chart for German child language which has been developed in our research group (see Clahsen 1986b) consists of five developmental phases, ranging from the period when children predominantly use one-

Table 1. Recordings of data set (i)

\begin{tabular}{llclll}
\hline Name & $\begin{array}{l}\text { Age at } \\
\text { recording }\end{array}$ & $\begin{array}{l}\text { Time of } \\
\text { observation }\end{array}$ & $\begin{array}{l}\text { Number of } \\
\text { recordings }\end{array}$ & $\begin{array}{l}\text { MLU } \\
\text { at rec. I }\end{array}$ & $\begin{array}{l}\text { Type of } \\
\text { recording }\end{array}$ \\
\hline Andreas & 7.0 & 1 month & 2 & 1.71 & audio \\
Anja & 9.6 & 14 months & 2 & 1.46 & audio \\
Jonas & 6.6 & 13 months & 2 & 2.76 & video \\
Julia & 3.2 & 1 month & 2 & 1.76 & audio \\
Klaus & 4.6 & 1 month & 2 & 2.00 & audio \\
Markus & 4.7 & - & 1 & 1.50 & video \\
Patrick & 4.5 & - & 1 & 2.25 & video \\
Petra & 3.8 & 12 months & 3 & 2.11 & audio \\
Sven & 7.4 & - & 1 & 2.17 & video \\
Stefan & 4.8 & - & 1 & 2.31 & video \\
Wolfgang & 4.5 & - & 1 & 2.84 & video \\
\hline
\end{tabular}


word utterances up to the time when embedded clauses occur. For each phase, the profile provides the most typical grammatical structures which have been documented in empirical studies on normal German child language. The profile is based on all the available research studies dealing with the acquisition of German grammar, and we may assume, until evidence to the contrary is available, that the suggested phases represent particular states of the acquisition of grammar by normal German children. Thus, the profile chart is not just a linguistic description of the children's language, but it also allows us to identify the developmental level of language acquisition a particular dysphasic child has achieved.

The general result that emerges from the description of dysphasia within this framework is that the children have problems with the linguistic structures of the later phases IV and V (which are acquired by linguistically normal children at about three years of age), whereas the patterns of the early phases I and II do not cause any specific difficulties. Interestingly, however, not all the structures of the later phases are inaccessible to dysphasic children. Rather, we find that some structures, even of the latest phase $V$, are used by the children, and that others (belonging to earlier phases in linguistically normal children) have not been acquired. This suggests that dysphasia cannot simply be accounted for in terms of a general retardation of the development of language. Detailed analyses are necessary in order to find out the specific linguistic deficits of these children.

The analysis of data set (i) has already been completed (Clahsen 1988). In the following, I will present some of the results we have gathered for these data. Currently, our research group is analyzing the data of the larger study (ii). In Table 1 some background information on data set (i) is given.

\section{Results}

As mentioned above, little is known about dysphasia in German-speaking children, either about the characteristic linguistic features or about the possible causes. In the clinical context, Liebmann's (1901!) classification of dysphasia is still in use (see Dannenbauer 1983). This system is just an unsystematic collection of some salient features of a child's linguistic behavior which is completely out of date, given the state of the art in firstlanguage-acquisition research. Our project should contribute to improving the diagnosis of dysphasia and its theoretical understanding. Within the linguistic framework adopted in our study, this presupposes a detailed description of the grammatical systems developed by these children. In what follows, I will first briefly go through some of the results on word 
classes and types of constituents. I will then focus on word order, particularly on verb placement in relation to verb morphology.

\subsection{Word classes and inflection}

This section presents summaries of the results on noun phrases, determiners, articles, verbal elements, case markings, and verb inflections. The results are based on distributional analyses of data set (i) mentioned above; these analyses are presented in the larger study (Clahsen 1988). Consider first the use of nominal elements and the structure of NPs.

Noun phrases. We find that all the children use full NPs and pronouns; some examples are given in (3). In addition to that, there are individual differences with regard to the preferred forms; some children prefer nominal reference, others pronominal reference. This is similar to the variation observed in normal children (see Bloom et al. 1975). Moreover, we cannot find any subject/object asymmetries in terms of the types of elements (pronouns or nouns) used for grammatical functions. All the children use attributive adjectives and/or determiners, that is, Det $+\mathrm{N}$ and/or $A d j+N$ patterns; there are, however, only very few cases of Det $+\mathrm{Adj}+\mathrm{N}$ where both are used within one NP. Finally, in the whole data there are no placement errors in the NP. Rather, the NP is head-final in all cases, as required in German.

I suggest phrase-structure rule (2) for these data. According to this rule, NPs may consist of a head noun and a determiner or adjective. Thus the grammar of dysphasic children provides for the positions required in phrase-structure syntax. Moreover, this is exactly the rule which is also acquired by normal children in the early stages of German $\mathrm{L} 1$ acquisition (see Clahsen 1988).

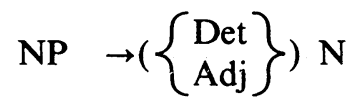

Determiners and articles. The children have problems with the use of determiners and articles. All the children use definite and indefinite articles, possessives, and quantifiers; in addition to these, one child also uses demonstratives. The data show that articles are often missing. No child consistently produces articles where they are required in the target language. There are some individual differences, but the mean percentage of missing articles is $55 \%$.

In addition, all the children have problems with the use of correct gender and number markings. There are two ways the children deal with 
this difficulty. Consider the examples given in (3). Some, for example Wolfgang, Jonas, and Klaus, use one or two invariant article forms (ein, de, die, etc.; see [3a]-[3e]) throughout, whereas in others, for example Petra, we find different forms, but many errors in the use of the required form (see [3f], [3g], [3h]). Finally, the longitudinal data do not show any systematic developmental progress in the use of articles. The deletion rates for articles do not decrease over time, and gender and number errors remain. It seems that problems with the use of articles are quite a stable feature of dysphasia.

(3) a. die tint auch ein bauch

(Wol)

( tint $=$ Kind $=$ 'child') 'The child needs one, too.'

b. ein tür is hab nich (is =ich =' I'; W. is looking for a door.)

c. un de kopfsauger haare komme hei ( $k$ opfsauger $=$ Klopfsauger, $h e i=$ rein) 'The hair should go into the vacuum cleaner.'

d. jetz kanne sech aba nit autstege de kamera (kanne $=$ kann, sech $=$ sich, autstege $=$ ausstellen) 'Now the camera cannot switch off by itself.'

e. und de tild ( tild = Schild) 'The shield (we need).'

f. un das po letzt (letzt $=$ verletzt) 'My backside is hurt.'

g. ich die lehrer bin 'I am the teacher.'

h. und du der das schulkind 'and you are the pupil.'

Verbal elements. Concerning verbal elements, we find that all the children use simple verbs, prefix verbs, and modals (see examples in [4]). As in German, modals may occur together with nonfinite verbal elements ([4g]) or in isolation ([4a], [4b], [4c]). Auxiliaries and copulas, however, are used in only very few cases. Moreover, the longitudinal data show that the proportion of deleted verbal elements decreases over time. No progress is made, however, in auxiliaries and copulas; we find high deletion rates and no systematic changes over time. It is interesting to note that all the children, even those who do not have auxiliaries, produce sentences with the verbal elements sein 'to be' and haben 'to have'; consider the examples (4d), (4e), (4f). In these cases, however, sein and haben are not used as auxiliaries, but rather as ordinary verbs, sein with locatives and haben with possessives. These data show that the required lexical forms are 
available to the children, and that the difficulties they have are restricted to the use of sein and haben as auxiliaries.

$$
\begin{aligned}
& \text { a. möcht nen arztkoffer } \\
& \text { 'want a doctor's case' } \\
& \text { b. ein zebra will } \\
& \text { 'a zebra want' } \\
& \text { c. } \ldots \text { darfe nit } \\
& \text { '. . may not' } \\
& \text { d. hier nich war num }
\end{aligned}
$$

(A. is seeking a number.)

e. ich $\mathrm{X}$ ein buch haben

(A. wants to have a book.)

f. hab schon?

$=$ 'Do you already have the toy?'

g. ich will was spielen

'I want to play something.'

h. meine metsa auch reintomm detz

= 'Mein Mädchen kommt jetzt auch rein' (W. puts a girl into a car).

Case markings. The data show that dysphasic children have many problems with the use of the case markings required in German (see examples in 5). Contrary to what is necessary in German, the children have only a binary case system with nominative forms and either accusatives or datives. None of the children studied produces both accusatives and datives. Moreover, there are only five examples with the genitive suffix $-s$ for possessives; in most cases, the genitive suffix is left out. In the produced case markings, we find many errors; the following types of case errors have been observed: (i) nom. where dat./acc. are required, (5c), (5d); (ii) acc. where dat. is required, (5e); (iii) dat. where acc. is required, (5f); (iv) acc./dat. for nonagent subjects, see (5g) and (5h). In addition, there is no case agreement within NPs. In (5a) and (5b), for example; the suffix $-n$ is required on the noun löwe and on the adjective große, since in German we have case agreement between the various elements of the NP. In all the data we have analyzed so far, there are no instances of case agreement in NPs. Rather, the case marking is only supplied once, in most cases on the article.

(5) a. fabian auch reißen mit den löwe

' $\mathrm{F}$. also tear (the page) with the lions (to pieces).'

b. und den doße tommel

$(d o ß e=$ große $)$ 'and the big drum' 
c. aber ich der hund spiel

'But I play the dog.'

d. $d u$ besser helf ich

lit. you $_{\text {NOM }}$ better help $\mathrm{I}_{\mathrm{NOM}}=$ 'I better help you.'

e. wat machen mit den tab?

( $t a b=$ Stab = stick) 'What can we do with the stick?

f. ich dir hinführen

'I will lead you there.'

g. den da is delb

( $\mathrm{K}$. is pointing to a yellow monkey.)

h. ihm kipsbein nachher kommt

( kommt $=$ bekommt $=$ 'gets', ihm $=$ Dat., Masc., Sing. $)$ 'He will get a plaster-cast afterwards.'

Error types (i), (ii), and (iii) have also been found in studies on normal German child language (Mills 1985; Tracy 1986; Clahsen 1984). It has been shown that the acquisition of case markings takes place comparatively late in German L1 development, approximately at the same time that the first embeddings occur. Still, normal children produce many case errors, typically over generalizations of nominative and accusative forms. These errors are due to the fact that the children initially develop a binary case paradigm with the dimension [ \pm subject]; [ + subj] gets nom. and all

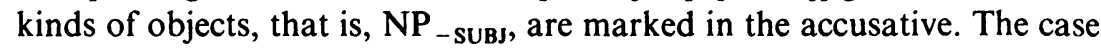
distinction between different kinds of objects is acquired later in development. Crucially, however, normal children use grammatical functions as dimensions to build up a case paradigm, even in their early binary system. This is in contrast to the dysphasic children.

The available data on case markings by dysphasic children suggest that they also have a binary case system. In the data we find that if the subject is an agent, it will be correctly marked in the nom. case. If, however, there are other thematic roles with the subject, such as in $(5 \mathrm{~g})$ and (5h), then there will be case errors with the subject. In examples of this kind, the accusative or dative is chosen on the basis of the thematic role of the subject. These errors suggest that dysphasic children focus on the semantic functions of case markings and that they use agentivity as the dimension to build up a case paradigm. Provided that the observed facts can be generalized, we have a binary case paradigm with nom. for [+ agentive] and nonnom. (either dat. or acc.) for [-agentive]. This is at least what can be drawn from the case markings available in the spontaneous speech samples. These data are, however, quite scanty. To be sure that our claims concerning case markings can be maintained, it is necessary to have more systematic data on case 
markings, particularly from the elicitation techniques we designed for the larger study.

Verb morphology. Essentially, the results demonstrate that it is subject-verb agreement that causes problems for the children on all levels of lexical representation, whereas other kinds of verb morphology, for example the rules for participles, are not disturbed.

We find that the children use uninflected stem forms (Ø), infinitive forms $(n)$ and the suffix $-t$ as regular verb forms. Consider the examples in (6). As in the early stages of normal German L1 development (see Clahsen 1986a), the suffix - $t$ is used with intransitives, and it does not encode subject-verb agreement (6j). Stems and infinitives are default forms which are used irrespective of the person or number of the subject; see (6a) to (6e). The suffix $-s t$ is not available to the children. There is only one exception to that, namely the third recording with the child Petra, to which I will return below. Moreover, the children have word forms of irregular verbs which are also possible in the adult language, for example, inflected variants of sein 'to be'; there are, however, many agreement errors with irregular verbs; see $(6 \mathrm{f})$ and $(6 \mathrm{~g})$. These data show that the children have problems building up a morphological paradigm for subject-verb agreement.

In contrast, participles are correctly inflected most of the time. First, there are no errors in the stems of irregular participles; examples such as * gefanden instead of gefunden do not occur. Second, all irregular participles are suffixed with $-\boldsymbol{n}$ as required in German; there are no errors such as *geganget, ${ }^{*}$ gefundet, etc. Third, regular participles are correctly suffixed with $-t$. The only source of errors is that strong verbs in German are categorized by the children as regular verbs, for example * gegeht instead of gegangen, or *gebratet instead of gebraten; see (6h) and (6i). This type of error is quite common, even with normal children.

(6) a. majo mann warten

(Mario is waiting for the man; required suffix: $-t$ )

b. is auch ein auto fahr

(W. is driving with a car; required: $-e /$ stem)

c. du auch ein haus mach

(While the therapist is building a house; required: $-s t$ )

d. uschi hier wohn?

$=$ 'Does U. live here?' (required: $-t$ )

e. mein baume fall

(W's trees fell down; required: -en)

f. das is puppen

'These are puppets' (required form: sind) 
g. hier zwei bäum is

'Here are two trees' (required form: sind)

h. die jetzt gebratet

= 'This will be fried' (required: $-e n$ )

i. ich ... einfach gegeht in schiff

'I simply went onto the ship' (required form: gegangen)

j. du dann runterfäll $t^{3}$

'Then you will fall down.'

The results on verb morphology suggest that dysphasic children do not have a general morphological deficit. Rather, their difficulties in this area seem to be restricted to subject-verb agreement. As long as the notion of grammatical agreement is not required, the children are able to correctly inflect verbal elements. This can be seen from the irregular verbs, such as the variants of sein 'to be' used by the children, which are possible wordspecific lexical entries in German, as well as from the correctly inflected participles, both regular and irregular.

\subsection{Verb placement}

3.2.1. In previous studies in German-speaking dysphasic children, verb placement has been an important focus of research. The available results, however, and the way they are interpreted are contradictory. As part of the project directed by Gerd Kegel in Munich, Günther (1981) studied retellings of picturebook stories by six dysphasic children. He found that the children always used the sentence pattern SVO. Kegel (1981) confirmed this result in sentence-repetition tasks. In the project directed by Hannelore Grimm in Heidelberg, eight dysphasic children are studied longitudinally. The results gathered by Grimm differ from those of Kegel's project. In Grimm (1983), it is shown that out of 134 sentences containing verbal elements, which were taken from one of the children studied, $112(=84 \%)$ are verb-final patterns. Similar figures are reported by Kaltenbacher and Kany (1985) for the other children studied in this project. The authors conclude that SOV is the typical dysphasic pattern ('dysphasische Sprache in Reinkultur'; see Grimm 1983: 176).

In these studies, verb placement has been picked out as a salient feature of the children's language, and it has been analyzed in isolation, without considering whether it is a finite or a nonfinite verb that appears in any given position. The notion of finiteness is, however, a crucial prerequisite for understanding verb placement in German. I will try to show that a more detailed linguistic analysis of the children's sentences will help to clarify the issue. 
I reanalyzed the data available from both projects with respect to the interaction between placement and inflection of verbs. The results can be summarized as follows:

a. The children studied in Grimm's project do not have subject-verb agreement. In most cases, the verbs are uninflected stems or infinitives which are placed clause-finally. There are a few cases of inflected verbal elements, and these are placed correctly, in second or first position; consider the following examples from Grimm (1983: 174):

(7) a. mama leine bauen

'M. alone build' - Inf.

b. die bolidei hat das

'The police has - 3.Pers.Sg. - it.'

c. hat mit runterfallen

'(Something) has (together) with (something else) fallen down.'

b. In the data presented to Kegel's project (see Hay et al. 1981), the person and number formatives are correctly supplied in most cases, and finite verbs are placed in second or first position, just as in German main clauses. In addition, there are a few cases of stem or infinitive forms; these are placed sentence-finally, just as in Grimm's data.

The reanalysis suggests that dysphasic children have the syntactic positions required for verb placement in German. Since uninflected stems or infinitives are used clause-finally and inflected verbal elements in second or first position, there are no particular verb-placement ERRORS. The acquisition of a morphological paradigm for subject-verb agreement, however, causes problems for them, particularly for the children studied in Grimm's project. Under this analysis, the observed verbplacement 'errors' appear to be secondary effects of the children's problems with inflection.

\subsubsection{A detailed analysis of the interaction between verb placement and} verb inflection has been carried out on the data from our project. The results on verb inflection have already been summarized in the previous section. As for verb placement, consider the frequencies in Table 2, which shows that verb-initial patterns are rare, and that the proportions of verbsecond and verb-final patterns vary, but that verb-final patterns are dominant for most of the children. Table 2 also shows that for some children there is a clear relative increase in the use of the verb-second pattern (Julia, Jonas, Petra), whereas for others the proportion of verbsecond patterns remains more or less stable (Anja, Andreas, Klaus). This suggests that, as opposed to the use of determiners and articles, progression in the use of verb-second is possible, at least for some children. 
Table 2. Verb placement

\begin{tabular}{llll}
\hline & $\begin{array}{l}\mathrm{X}^{*} \mathrm{~V} \mathrm{Y} \mathrm{Y}^{*} \\
\text { (in \%) }\end{array}$ & $\begin{array}{l}\mathrm{X}^{*} \mathrm{~V} \\
\text { (in \%) }\end{array}$ & $\begin{array}{l}\mathrm{VS}\left(\mathrm{X}^{*}\right) \\
\text { (in \%) }\end{array}$ \\
\hline Anja 1 & 16 & 84 & 0 \\
Anja 2 & 21 & 78 & 0 \\
Andreas 1 & 30 & 61 & 8 \\
Andreas 2 & 33 & 60 & 6 \\
Klaus 1 & 42 & 57 & 0 \\
Klaus 2 & 42 & 52 & 5 \\
Julia 1 & 9 & 81 & 9 \\
Julia 2 & 20 & 72 & 6 \\
Patrick & 54 & 36 & 9 \\
Sven & 49 & 43 & 6 \\
Stefan & 45 & 47 & 7 \\
Jonas 1 & 31 & 60 & 8 \\
Jonas 2 & 49 & 41 & 9 \\
Petra 1 & 18 & 81 & 0 \\
Petra 2 & 21 & 78 & 0 \\
Petra 3 & 31 & 68 & 0 \\
Wolfgang & 16 & 82 & 1 \\
\hline
\end{tabular}

Verb-second $\left(X^{*} V Y^{*}\right)$, verb-final $\left(X^{*} V\right)$, verb-first $\left(V S\left(X^{*}\right)\right)$.

In addition it has been shown (see Clahsen 1988: 205ff.) that there are qualitative asymmetries between verb-final patterns on the one hand and verb-initial and verb-second patterns on the other hand. Verb-final patterns are used with uninflected verbal elements (stems), infinitives, and participles, whereas the front (first or second) verb position is dominantly covered by regularly inflected verbs with the suffix - $t$ (except for participles) and imperatives, by irregular verbs, such as the inflected forms of sein 'to be', wissen 'to know', etc., and by modals and auxiliaries.

Consider as an illustration of this the cases of Wolfgang and Petra; the examples in (8) are taken from Wolfgang, those in (9) from the third recording with Petra.

(8) a. ein titz is bauch

$$
\text { = 'I need a seat.' }
$$

b. meine metsa auch reintomm detz

'Mein Mädchen kommt jetzt auch rein' (W. puts girl into car).

c. is ein titz bauch (compare [8a])

d. is auch ein auto fahr (is $=\mathrm{ich}=$ ' $\mathrm{I}$ ', W. is driving a car.) 
e. is haus mach detz

( $\operatorname{det} z=$ jetzt = 'now'; W. is building a house.)

f. du auch ein metsa hol

( metsa $=$ Mädchen = 'girl') = 'You are fetching a girl' .

g. is hier wohn ne?

$(i s=\mathrm{ich})=$ 'Do I live here?'

h. is ers haus bau

(W. is building a house.)

i. du mis ein geb

lit. 'You me one give' (W. wants to have a toy).

j. diesa mötz nich immer

(mötz $=$ möcht $=$ 'want' lit. 'this want not always' (W. does not want to have that toy).

(9) a. und jetzt du wieder schreibst

'and now you again write'

b. und dann der andere wieder werft

'and then the other throws'

c. wie der läuft?

= 'How does he run?'

d. ich will was spielen

='I want to play something.'

As is clear from the examples in (8), W. does not use person and number formatives. Thus, he cannot distinguish between finite and nonfinite verbal elements. This distinction, however, is required to correctly apply the verb-second constraint of German. Instead, W. prefers verb-final placement (see Table 2), which is correct in German for nonfinite verbal elements. Lexical verbs in the front verb position are very rare. Example $(8 \mathrm{j})$ is a case of verb-second; all the other examples in (8) are analyzed as verb-final placements; additionally we have extrapositions of one constituent in (8b) and (8e) (see Clahsen 1988: 197ff. for further comments). Modals are dominantly placed in the front verb position (see [8j]), thus showing that $\mathrm{W}$. has two distinct verb positions in the syntax. Therefore, it is not necessary (with regard to verb placement) to assume a syntactic deficit for W.

Petra is in some respects different from the other dysphasic children studied so far. She is the only child who has (in recording 3) acquired correct subject-verb agreement. Petra also differs from normal children. She leaves ordinary finite verbs in clause-final position (see [9a], [9b], [9c]). Only modals are consistently placed in the front verb position (see [9d]). In normal children, the verb-second constraint is available as soon as the agreement paradigm has been acquired. This is not the case with Petra. 
The data show that this cannot be due to the unavailability of the subject-verb agreement system, as was the case with Wolfgang, since Petra has the correct agreement paradigm. Furthermore, it is not necessary to assume a syntactic deficit for Petra, since the required verb positions are available to her. I would rather suggest that Petra's verbplacement preferences can be accounted for in terms of problems she has with the categorization of verbal elements. This will be made explicit in the following grammatical analysis. ${ }^{4}$

3.2.3. The theoretical framework I adopt to analyze the results on verb placement and verb inflection in dysphasic children is the INFL/V parameter suggested by Kratzer (1984). The basic idea is that dysphasic children have problems with the morphological categorization of verbal elements as well as with building up an agreement paradigm, and not so much with the acquisition of syntactic rules.

The INFL/V parameter is crucial for the peculiarities of verb placement in German. Kratzer argues that there is a close connection between strength of inflection and word order, particularly verb placement. Under the assumptions that affixes are assigned syntactic categories and that verb inflections are INFLs, she establishes word-formation rules in the morphological component of the lexicon which incorporate INFL, as in (10a) or in (10b):

(10) a. INFL[V INFL]
b. v[V INFL]

The choice between (10a) and (10b) is determined by the strength of inflection; strong INFLs such as tense or agreement features are of type (10a), while infinitives and other types of weak INFLs are projected according to (10b). Now, the INFL parameter claims that it is a matter of parametrical variation among languages whether particular INFLs are strong or weak. Given that German finite verbs have strong inflections, morphology will yield configurations like (10a) for them. This ensures that in German any kind of finite verb can occur in the initial position of the sentence. In contrast, English finite verbs have weak inflections. Since the configurations provided by the morphology are dominated by $\mathrm{V}$ nodes, they cannot be projected into the INFL node in the syntax. Auxiliaries and modals, however, are lexically specified as INFLs, even in English; therefore they can appear in the initial position under the syntactic INFL node.

Given this framework, I suggest that dysphasic children have acquired the correct syntactic configuration which is required in German for main clauses. This offers the children two landing sites for verbal elements in 
the phrase-structure tree: INFL, the head of S, and V, the head of VP; see (11).

$$
\left[\mathrm{X}^{\max }[\mathrm{INFL} \ldots[\mathrm{vp} \ldots \mathrm{V}]]\right]
$$

The data suggest that such a syntactic INFL position is part of the phrase-structure tree available to dysphasic children. We found that modals are consistently fronted as required in German (see [9d]). According to common linguistic assumptions, modals have meanings that make them classical candidates for the category INFL (or AUX in older studies), regardless of their inflections (see Steele 1981). Thus modals can be said to be categorized as INFLs in the children's lexicon. Since the agreement system is not available to dysphasic children (except for Petra 3 ), however, and verb inflections are weak, ordinary verbs are categorized as Vs rather than as INFLs in the morphology and can therefore not be fronted into the INFL position. This is reflected in the predominant use of verb-final patterns, as has been observed for the children studied in Grimm's project as well as for those studied in our project.

Under this analysis, the verb-placement patterns which have been observed for dysphasic children can no longer be regarded as evidence for a syntactic deficit but, rather, turn out to be secondary effects of the children's problems with the use of inflection. Moreover, the two cases mentioned above, Wolfgang and Petra, illustrate different types of problems with inflection. W. cannot establish a morphological agreement paradigm. Person and number formatives are not available to him. He prefers uninflected (stem) forms or default forms (-en). Most of the dysphasic children studied so far are similar to $W$. in these respects. The system Petra develops is different, but it can also be described in terms of the above-mentioned grammatical analysis. P. inserts those verbal elements which are directly categorized as INFLs into the correct position in the syntax. Ordinary finite verbs, however, which are built up by wordformation rules, are not categorized as INFLs. Petra treats these verbs just like nonfinite verbal elements and inserts them into the $\mathrm{V}$ position of (11). For P. agreement inflections are 'weak', just as in English. They cannot serve as a trigger to recategorize a verbal element from $V$ to INFL. Again, this appears to be a selective problem, and the solution Petra comes up with does fall within the range of possible grammars.

\subsection{Argument order}

In functional terms, the order of the arguments in the clause may be regarded as part of the coding devices for grammatical relations. It has a 
function similar to that of case markings and (subject-verb) agreement markings. In German, there is some interaction between these different surface-structure markings. Consider (12):

(12) Die Frau begrüßt die Tante.

'The woman greets the aunt.'

(=a. 'The woman greets the aunt.')

(=b. 'The aunt greets the woman.')

In examples such as (12) neither case nor agreement markings are reliable indicators of grammatical relations. Note further that in contrast to English, both interpretations (a) and (b) are possible, since in German the position before the finite verb can be filled with the subject or the object NP. In the unmarked case, however, the first NP is interpreted as the subject. Thus, reading (a) is preferred over reading (b), other things being equal. This shows that word order also contributes to the encoding of grammatical relations.

Given our claim that dysphasic children are able to construct possible grammars, we would expect that (similarly to normal children) they develop a system for distinguishing between different grammatical relations. From our hypothesis of a selective morphological deficit in dysphasia we would, however, expect that in this system the children have to rely on argument order and cannot make use of case and agreement markings. In order to test these claims, the sentences used by the children have been analyzed in terms of the prototypical participants, agents (A) and patients $(\mathrm{P})$, as well as in terms of two types of verbs, transitives $\left(\mathrm{V}_{t}\right)$ and intransitives $\left(\mathrm{V}_{\mathrm{i}}\right)$; see Comrie (1981). The quantitative results are shown in Table 3. Consider also the examples in (13).
a. geht nich so eine
(P. is trying to bring together two toy blocks.)
b. kommt dein auto
(S. is driving with the therapist's toy car.)
c. ein tür is hab nich
(is = ich = 'I'; W. does not have a door )
d. ein titz is bauch
= 'I need a seat.'
e. wiederkomme ich

(A. has come back.)

The canonical sentence schema (Slobin and Bever 1982) used by the dysphasic children is $\mathrm{A}<\mathrm{P}<\mathrm{V}$. As is clear from Table 3, most of the children's sentences belong to this pattern or to one of its variants (PV or AV). Three kinds of order patterns have been observed that differ from 
Table 3. Argument order

\begin{tabular}{lrrrrrrrr}
\hline & A & & A & & A & P & A & \\
& P & P & $\mathbf{V}_{\mathbf{t}}$ & $\mathbf{V}_{\mathbf{t}}$ & $\mathbf{V}_{\mathbf{t}}$ & $\mathbf{V}_{\mathbf{i}}$ & $\mathbf{V}_{\mathbf{i}}$ & Other \\
& $\mathbf{V}_{\mathbf{t}}$ & \multicolumn{1}{c}{$\mathbf{V}_{\mathbf{t}}$} & $\mathbf{P}$ & $\mathbf{P}$ & & & & \\
\hline Anja 1 & 0 & 10 & 0 & 0 & 1 & 1 & 1 & 1 \\
Anja 2 & 5 & 29 & 1 & 4 & 8 & 2 & 8 & 7 \\
Andreas 1 & 1 & 3 & 1 & 5 & 1 & 8 & 3 & 5 \\
Andreas 2 & 2 & 22 & 0 & 10 & 2 & 3 & 2 & 6 \\
Klaus 1 & 1 & 7 & 2 & 2 & 0 & 3 & 0 & 1 \\
Klaus 2 & 1 & 11 & 0 & 6 & 0 & 11 & 2 & 10 \\
Julia 1 & 5 & 8 & 0 & 0 & 7 & 5 & 1 & 2 \\
Julia 2 & 11 & 7 & 3 & 0 & 6 & 12 & 5 & 8 \\
Patrick & 2 & 16 & 3 & 6 & 1 & 9 & 1 & 16 \\
Sven & 10 & 8 & 5 & 0 & 7 & 26 & 9 & 26 \\
Jonas 1 & 3 & 31 & 4 & 3 & 9 & 14 & 2 & 9 \\
Jonas 2 & 5 & 4 & 7 & 5 & 6 & 10 & 4 & 16 \\
Petra 1 & 2 & 4 & 1 & 0 & 0 & 1 & 0 & 0 \\
Petra 2 & 7 & 4 & 2 & 2 & 7 & 17 & 22 & 4 \\
Petra 3 & 12 & 5 & 16 & 0 & 4 & 15 & 17 & 11 \\
Wolfgang & 20 & 13 & 2 & 3 & 11 & 39 & 1 & 9 \\
\hline
\end{tabular}

the canonical schema: (i) the intransitive pattern $\mathrm{V}_{\mathrm{i}} \mathrm{P}$ : see (13a) and (13b); (ii) topicalizations $\left(\mathrm{PAV}_{\mathrm{t}}\right.$ ): see (13c) and (13d); (iii) the intransitive pattern $\mathrm{V}_{\mathrm{i}} \mathrm{A}$ : see $(13 \mathrm{e})$. These patterns have been analyzed under 'Other' in Table 3. Of these three, type (i) is by far the most frequent. Topicalizations are used by only some of the children, and pattern (iii) occurs in just a few scattered examples.

Given these observations, the order of arguments in the sentences used by the dysphasic children can be described in terms of the rules in (14).
a. $\mathrm{A}<\mathrm{V}$
b. $\mathbf{A}<\mathbf{P}$

According to (14), A (if present) occurs preverbally and before $P$, while the position of $P$ in relation to the verb is variable. These results show that the children use word order as a coding device to distinguish between the arguments of the transitive clause. This basic system is also used by normal German children, at least in the early stages in which subject-verb agreement and case markings have not yet been acquired.

\subsection{Summary}

We found that dysphasic children have problems mainly in the areas of inflectional morphology and of grammatical function words. The various 
parts of grammatical inflection are, however, not equally disturbed. The focus seems to be a deficit in grammatical agreement. One of the effects of this is an unbalanced development of grammatical competence in these children. This is clear, for example, from the results on verb morphology, where it has been shown that subject-verb agreement is not available to dysphasic children (with the exception of Petra 3), while other kinds of verbal morphology, such as the rules for inflecting participles, do not cause particular problems for the children. In addition, we found with respect to word order that there are no placement errors within constituents, and that the apparent verb-placement 'errors' are in fact secondary effects of the children's problems with verbal morphology. With respect to articles, the data show that all the children use definite and indefinite articles correctly and that their problems with articles are restricted to the markings of gender and number. With reference to verbal elements, we found that the children have problems with auxiliaries and copulas, while modals are consistently used by all the children. With respect to case markings, the data show that there is no case agreement within NPs. In addition, the semantic notion of agentivity is used as a dimension in the children's case paradigm. Finally we found that the children use word order to distinguish grammatical relations.

\section{Conclusion}

As a general conclusion from the descriptive results we may characterize dysphasia in terms of a selective deficit of an otherwise normal linguistic system. Dysphasic children have problems in establishing agreement relations in grammar, that is, structural relations between two elements in which one element asymmetrically controls the other. This could be formally represented in terms of the control-agreement principle from GPSG (Gazdar et al. 1985: 89). This condition accounts for the structures which are blocked in dysphasia as well as for those which are still accessible to the children.

Consider, for example, the case of articles. Gender is not a primary feature of articles. It is, rather, assigned to articles in local NP trees in which the noun asymmetrically controls the article. Thus, gender can be subsumed under the general notion of grammatical agreement. In contrast to gender, notions such as definiteness and indefiniteness are inherent features of articles and can be acquired through semantic bootstrapping (see Pinker 1984). Note that all the children have established a paradigm with different forms to encode the distinction between definites and indefinites. This suggests that the children do not have 
general morphological problems, but that their deficit is restricted to grammatical agreement.

Consider as a second example the use of verbal elements. Modals have their own meanings which make them classic candidates for the category INFL. Therefore, modals can be correctly categorized with semantic bootstrapping. This strategy cannot, however, be used with auxiliaries and copulas. These verbal elements may rather be analyzed as lexical fillers of the agreement features. In this respect, auxiliaries and copulas are similar to inflectional formatives. Both are represented in morphological paradigms which are constructed along agreement features. Therefore, the fact that dysphasic children have problems in categorizing auxiliaries and copulas, but not modals, is in accordance with our claim of a selective deficit with grammatical agreement.

The results on case markings and on verb morphology are also consistent with that claim. Case markings on NPs and agreement suffixes on verbal elements are not primary features of these constituents but are rather assigned to these constituents in local phrase-structure trees by a controlling element; with case markings, the controller is typically a verb, and with agreement suffixes, it is the subject. Thus, both phenomena can be subsumed under the general notion of control agreement mentioned above. The data show that dysphasic children have problems building up a case paradigm for grammatical functions, and that they seem to focus on the semantic function of case markings. Moreover, we found that those parts of verbal morphology that do not involve grammatical agreement are undisturbed. This can be seen from the fact that dysphasic children use the rules required for inflecting participles in German, and that, similarly to the early stages of normal German child language, the verb suffix $-t$ encoding semantic intransitivity is available in the dysphasics' verb-inflection paradigm (see note 3 ). These results demonstrate quite clearly that the deficit is restricted to the area of agreement.

A further conclusion from the descriptive results is that the linguistic systems developed by dysphasic children fall within the range of parameters of universal grammar. It was not necessary to assume bizarre rule systems in order to describe the linguistic patterns used by the children; they could, rather, be analyzed in terms of grammars that are possible for human language.

An unexpected result of the study is that we could not find a lot of variation among the children. Given that the notion of dysphasia does not cover a homogeneous population, we expected to find several different types of this syndrome. The data from ten children which we have analyzed so far are, however, far more homogeneous than expected. There are some individual differences, which were illustrated with the data 
from Wolfgang and Petra, but on the whole, it was not possible to. establish a linguistically based typology of dysphasia. The larger project in which 20 children are being studied longitudinally should help to clarify this issue.

In addition, it is necessary to carry out cross-linguistic studies on dysphasia. This is required given that the underlying linguistic deficit has to be described irrespective of the structure of a particular language. Consider, for example, the data in (15) which come from a case study carried out by Gopnik (1985) on dysphasia in English child language:

a. you got a tape recorders

b. the four bus go in Boucherville

c. when the cup break he get repair

d. the Marie-Louise look at the bird

e. the superman is say good-bye and hiding

f. the ambulance arrive

g. the restaurant is upstairs

h. is everything true?

i. will farmer cut in July?

Here we find patterns similar to the German data described above. The child has problems with number agreement in the NP, with the choice of the correct article, with auxiliaries, and with subject-verb agreement. In phrase-structure syntax, however, the child does not have problems. Word order is correct, and even yes/no questions are constructed with inversion of subject and auxiliary. At present, these examples are no more than suggestive. Clearly, more data from different languages are required, in order to demonstrate that our view of dysphasia has some crosslinguistic significance.

Received 19 October 1988

University of Düsseldorf

Revised version received

18 June 1989

\section{Notes}

* This is a revised version of a paper presented at the conference on 'The structure of the simple clause in language acquisition', Max-Planck-Institut für Psycholinguistik, Nijmegen, November 9-13, 1987. I am grateful to Anne Mills, Günther Peuser, Chris SchanerWolles, and an anonymous reviewer for Linguistics for comments on earlier versions. The research in the present paper has been supported by two grants from the Deutsche Forschungsgemeinschaft (DFG), grants No. WU 86/9-1 and 9-2. Correspondence address: Institut für Allgemeine Sprachwissenschaft, Universität Düsseldorf, Universitätsstrasse 1, D-4000 Düsseldorf, Federal Republic of Germany.

1. Our research group was established in 1981 at the University of Wuppertal and is 
currently working at the Seminar für Allgemeine Sprachwissenschaft of the University of Düsseldorf. At present the group has six researchers, Birgit Puschmann, Monika Rothweiler, Beate Uzarewicz, Andreas Collings, Andreas Woest, and myself.

2. The notion of linguistic profiles has been developed for use in the assessment of language disorders, particularly with regard to grammatical disabilities in children (see Crystal 1982). The best-known profile currently available came to be known as LARSP, the Language Assessment Remediation and Screening Procedure (Crystal et al. 1976). Based on a descriptive synthesis of the L1/English-acquisition literature, a set of seven developmental stages is suggested. At each stage, LARSP provides those grammatical structures which are commonly used by normal children. Recently, the profiling approach has been applied to languages other than English; see Berman et al. (1982) for the Hebrew profile HARSP; Admiraal-Berg et al. (1984) and Verhulst-Schlichting (1982) for the Dutch profile; and Clahsen (1986b) for the German profile.

3. Note that verbs with the suffix - $t$ (except for participles) are dominantly placed in first or second position. Thus, with respect to verb placement, cases such as (6j) are exceptional. Under the analysis which will be given in the next section the verb suffix $-t$ is regarded as an INFL in the children's lexicon just as are modals. Modals and verbs with the intransitive suffix $-t$ are similar with respect to verb placement; that is, they are both in the front verb position in most cases. These similarities can be derived from the proposed lexical categorization (see Clahsen 1988).

4. One of the reviewers for Linguistics has suggested an alternative analysis for the data from Petra 3. The proposal is that Petra does not use subject-verb inversion. The reviewer argues that this is mainly the case in utterances that begin with und dann (see [9b]) and that if it can be assumed that und dann syntactically functions as und, the verb position is basically correct.

The problem with this proposal is that it does not account for the data of Petra 3. Here I only refer to examples from the material published in Clahsen (1988); there are even more examples of a similar sort in the complete transcripts. Consider the following cases:

(i) hier will ich malen.

'Here I want to paint something.'

(ii) ich dir sag gar nicht.

'I don't tell you (that).'

(iii) ich jetzt mach.

'I'll do (that) now.'

(iv) der immer füsche ehm angelt.

'He used to go fishing.'

In (i), we have a clear case of superficial inversion. According to my analysis, the modal verb will is in the INFL position in this case. In the other examples, finite verbs are in sentence-final position and objects or adverbs before them. Thus, these cases are instances of SXV, and subject-verb inversion is not required. These data suggest that the use of verb-final patterns cannot be due to Petra not having subject-verb inversion.

\section{References}

Admiraal-Berg, C., Bol, G., Kuiken, F., and Verwey-de Jongh, T. (1984). Handleiding voor een grammaticale analyse van taalontwikkelingsstoornissen. Amsterdam: Instituut voor Algemene Taalwetenschap.

Berman, R., Rom, A., and Hirsch, M. (1982). Working with HARSP, Hebrew adaptation of LARSP. Unpublished manuscript, University of Tel-Aviv. 
Bloom, L., Lightbown, P., and Hood, L. (1975). Structure and variation in child language. Monographs of the Society for Research in Child Development 40.

Chomsky, N. (1986). Knowledge of Language. New York: Praeger.

Clahsen, H. (1984). Der Erwerb von Kasusmarkierungen in der deutschen Kindersprache. Linguistische Berichte 89, 1-31.

-(1986a). Verb inflections in German child language. Acquisition of agreement markings and the functions they encode. Linguistics 24, 79-121.

-(1986b). Die Profilanalyse. Berlin: Marhold.

-(1988). Normale und gestörte Kindersprache. Linguistische Untersuchungen zum Erwerb von Syntax und Morphologie. Amsterdam: Benjamins.

Comrie, B. (1981). Language Universals and Linguistic Typology. Oxford: Blackwell.

Crystal, D. (1982). Profiling Linguistic Disability. London: Arnold.

-, Fletcher, P., and Garman, M. (1976). The Grammatical Analysis of Language Disability. London: Arnold.

Dannenbauer, F. M. (1983). Der Entwicklungsdysgrammatismus als spezifische Ausprägungsform der Entwicklungsdysphasie. Birkach.

Gazdar, G., Klein, E., Pullum, G., and Sag, I. (1985). Generalized Phrase Structure Grammar. Oxford: Blackwell.

Gopnik, I. (1985). Featureless grammar. Unpublished manuscript, McGill University, Montreal.

Grimm, H. (1983). Kognitions- und interaktionspsychologische Aspekte der Entwicklungsdysphasie. Sprache und Kognition 3, 169-186.

Günther, H. (1981). Untersuchungen zum Sprachverhalten agrammatischer Kinder mit Ziel- und Modellsatzmethode. In Psycholinguistische Untersuchungen zum kindlichen Agrammatismus, G. Kegel and H. Günther (eds.), 35-59. Munich: Institut für Phonetische und Sprachliche Kommunikation.

Hay, G., Hummel, Y., Günther, H., and Meßing, J. (1981). Dokumentation von Daten und Fehleranalysen zum kindlichen Agrammatismus. In Psycholinguistische Untersuchungen zum kindlichen Agrammatismus, G. Kegel and H. Günther (eds.), 81-213. Munich: Institut für Phonetische und Sprachliche Kommunikation.

Hyams, N. (1986). Language Acquisition and the Theory of Parameters. Dordrecht: Reidel.

Kaltenbacher, E., and Kany, W. (1985). Kognitive Verarbeitungsstrategien und Syntaxerwerb bei dysphasischen und sprachunauffälligen Kindern. In Dysgrammatismus, I. Füssenich and B. Gläß (eds.), 180-219. Heidelberg: Schindele.

Kegel, G. (1981). Zum Einfluß von Syntax und Semantik auf die Nachsprechleistungen agrammatischer Kinder. In Psycholinguistische Untersuchungen zum kindlichen Agrammatismus, G. Kegel and H. Günther (eds.), 61-80. Munich: Institut für Phonetische und Sprachliche Kommunikation.

Kratzer, A. (1984). On deriving syntactic differences between English and German. Unpublished manuscript, Technical University, Berlin.

Liebmann, A. (1901). Agrammatismus infantilis. Archiv für Psychiatrie 34, 240-252.

Mills, A. (1985). The acquisition of German. In The Cross-Linguistic Study of Language Acquisition, D. Slobin (ed.), 141-254. Hillsdale, N.J.: Erlbaum.

Pinker, S. (1984). Language Learnability and Language Development. Cambridge, Mass.: MIT Press.

Slobin, D., and Bever, T. (1982). Children use canonical sentence schemas: a cross-linguistic study of word order and inflection. Cognition 12, 229-265.

Tracy, R. (1986). The acquisition of case morphology in German. Linguistics 24, 47-78.

Verhulst-Schlichting, L. (1982). Handleiding bij de voorlopige nederlandse versie van de LARSP profielkaart. Unpublished manuscript, University of Utrecht.

Steele, S. (1981). An Encyclopedia of Aux. Cambridge, Mass.: MIT Press.

Wyke, M. (ed.) (1978). Developmental Dysphasia. New York: Academic Press. 